\title{
TITIK-ANTARA DI DALAM RUANG METRIK DAN RUANG INTERVAL METRIK
}

(Between-Points In Metric Space And Metric Interval Space)

\author{
MOZART W TALAKUA \\ Jurusan Matematika, FMIPA,UNPATTI \\ Jl. Ir. M. Putuhenam, Kampus Unpatti, Poka-Ambon \\ E Mail: ocat_08@yahoo.com
}

\begin{abstract}
A point $p$ in metric space $(X, d)$ is called a between-point of $a, b \in X$ if $d(a, b)=d(a, p)+d(p, b)$. This concept was formulated by Menger in 1928. If all the between-points of $a$ and $b$ is collected in a set, then $a$ and $b$ are that set automaticlly. In the metric space $(X, d)$ and if there are operator $A_{d}$ in $X$, hence this interval operator is called metric interval operator. The couple of $\left(X, A_{d}\right)$ is called metric interval space.
\end{abstract}

Keywords: Between-points, Metric Space, Metric Interval Space

\section{PENDAHULUAN}

Pada tahun 1906 Maurice Frechet yang adalah seorang ahli matematika berkebangasaan Perancis memperkenalkan konsep jarak pada himpunan yang tidak kosong. Jarak ini selanjutnya disebut metrik pada himpunan tadi. Himpunan $X$ yang tidak kosong dilengkapi metrik $d$ ditulis $(X, d)$ disebut ruang metrik sedangkan anggota-anggota himpunan $X$ disebut titik-titik pada ruang metrik yang termuat dalam bilangan riil $d(x, y)$ adalah jarak titik $x$ dan $y$ didalam $(X, d)$.

Di dalam lingkup analisis membicarakan tentang ruang metrik merupakan suatu hal yang sangat penting, sebab ruang metrik banyak digunakan di dalam membicarakan kekonvergenan suatu barisan atau kekontinuan suatu fungsi. kekonvergenan suatu barisan atau kekontinuan suatu fungsi merupakan salah satu bahasan utama dalam analisis.

Perhatikan kembali pengertian titik-antara di dalam sistem bilangan riil. Bilangan riil $p$ berada diantara dua bilangan riil $a$ dan $b$, jika $a \leq p$ dan $p \leq b$, yang selanjutnya ditulis $a \leq p \leq b$. Dengan menggunakan interval, $p$ yang berada diantara $a$ dan $b$ dapat ditulis $p \in[a, b]$.

Lebih lanjut konsep titik diantara dua titik pada suatu sistem bilangan riil $\mathbf{R}$ bukanlah suatu hal yang aneh dalam analisis. Akan tetapi titik-antara dua buah titik pada ruang metrik $(X, d)$ merupakan suatu hal yang menarik untuk dibicarakan dan diteliti.

Menurut definisinya, jika $a$ dan $b$ dua buah titik di dalam ruang metrik $(X, d)$, maka tidak ada titik yang terletak diantaranya. Berawal dari kondisi inilah munculnya permasalahan yang akan dibahas dalam karya tulis ini.

Pembicaraan titik-antara di dalam ruang metrik menjadi lebih menarik, setelah pada tahun 1928 Menger pertama kali memperkenalkan definisi titik-antara dua buah titik di dalam ruang metrik $(X, d)$. Definisi dimaksud adalah : Titik $p$ di dalam ruang metrik $(X, d)$ berada diantara titik $a$ dan $b$ didalam $X$ jika $d(a, b)=d(a, p)+d(p, b)$.

Dalam definisi tersebut terdapat dua kelompok titikantara, yaitu titik-antara sejati dan titik-antara tidak sejati. Hal tersebut dibedakan berdasarkan apakah $p$ sama atau tidak dengan $a$ dan $b$. Dengan demikian yang dimaksud dengan titik-antara sejati dalam ruang metrik $(X, d)$ didefinisikan sebagai berikut : Titik $p$ di dalam ruang metrik $(X, d)$ berada diantara titik $a$ dan $b$ di dalam $X$ jika $p \neq a, p \neq b$ dan $d(a, b)=d(a, p)+d(p, b)$

Berdasarkan definisi itu, maka munculah beberapa pertanyaan sehubungan dengan titik-antara $p$ tersebut, diantaranya : Bagaimanakah hubungan antara $p$ dengan $a$ dan $b$ ? Sifat-sifat apakah yang mencirikan keberadaan titik $p$. Jika $A_{d}$ merupakan interval metrik yang memuat semua titik $p$, sifat-sifat apakah yang berlaku di dalam interval tersebut?

Hal-hal itulah yang merupakan permasalahan yang akan dibahas dalam karya tulis ini. Sistem pembahasannya akan diutamakan dalam mencari teorema-teorema (sifat-sifat) yang merupakan sifat-sifat titik-antara di dalam ruang metrik $(X, d)$.

\section{TINJAUAN PUSTAKA}

Sistem bilangan riil pada dasarnya mempunyai dua sifat, yaitu : pertama, sifat aljabar. Sifat ini secara singkat dikatakan bahwa himpunan bilangan riil $\mathbf{R}$ bersama-sama dengan operasi biner penjumlahan dan perkalian membentuk suatu lapangan (field). Kedua, sifat yang membahas tentang jarak antara dua buah titik dan 
pembahasan tentang konsep limit. Sifat ini disebut sifat metrik atau topologis.

Sifat metrik yang awalnya diperkenalkan oleh Maurice Frechet sekitar tahun 1906 dalam tesisnya yang berjudul sur quelques points du calcul functionnel, membicarakan tentang fungsi-fungsi pada kalkulus. Disini Frechet berusaha memperkenalkan konsep dari suatu ruang metrik $(X, d)$. Kemudian oleh Menger pada tahun 1928 dengan berpatokan pada pengertian ruang metrik $(X, d)$ serta sifat-sifat yang berkaitan dengannya, maka diperkenalkan pengertian titik-antara didalam ruang metrik dan ruang interval metrik. Selanjutnya didukung oleh beberapa literatur lain, maka penulis mencoba menyusun sebuah penulisan tentang titik-antara didalam ruang metrik dan ruang interval metrik melalui definisi, contoh serta beberapa teorema yang berkaitan.

\section{Definisi 1}

Suatu himpunan $X$ yang tidak kosong didefinisikan sebagai berikut :

(i) Fungsi $d: X \times X \rightarrow \mathbf{R}$ yang memenuhi empat sifat, yaitu:
a.) $d(x, y) \geq 0$ untuk setiap $x, y \in X$,
b.) $d(x, y)=0$ jika dan hanya jika $x=y$,
c.) $d(x, y)=d(y, x)$ untuk setiap $x, y \in X$,
d.) $d(x, y) \leq d(x, z)+d(z, y)$ untuk setiap $x, y, z \in X$,

disebut metrik (metric) atau jarak (distance) pada $X$.

(ii) Himpunan $X$ yang dilengkapi dengan suatu metrik $d$, dituliskan dengan $(X, d)$ disebut ruang metrik (metric space). Selanjutnya, jika metriknya telah diketahui (tertentu) maka ruang metrik cukup ditulis $X$ saja.

(iii) Anggota ruang metrik $(X, d)$ disebut titik (point) dan untuk setiap $x, y \in X$ bilangan nonnegatif $d(x, y)$ disebut jarak (distance) titik $x$ dengan titik $y$.

\section{Teorema 1}

(i) $M$ batas atas terkecil (suprimum) himpunan $A$ jika dan hanya jika
a.) $M$ batas atas $A$, untuk setiap $a \in A$ berakibat $a \leq M$, dan
b.) Untuk setiap bilangan $\varepsilon>0$ terdapat $a^{\prime} \in A$ sehingga

$$
M-\varepsilon<a^{\prime} \leq M
$$

(ii) $m$ batas bawah terbesar (infimum) himpunan A jika dan hanya jika

a.) $m$ batas bawah $A$, untuk setiap $a \in A$ berakibat

$$
m \leq a, \text { dan }
$$

b.) Untuk setiap bilangan $\varepsilon>0$ terdapat $a " \in A$ sehingga

$$
m \leq a^{\prime \prime}<m+\varepsilon
$$

\section{Teorema 2}

Jika $A, B \subset \mathbf{R}$, dan terbatas maka :

(i) $\sup (A+B) \leq \sup (A)+\sup (B)$

$$
\sup (A+B) \geq \inf (A)+\inf (B)
$$

\section{Definisi 2 (Titik-antara Sistem Bilangan Riil)}

Suatu bilangan riil $p$ berada diantara dua bilangan riil $a$ dan $b$, jika $a \leq p$ dan $p \leq b$, yang selanjutnya ditulis $a \leq p \leq b$. Dengan menggunakan interval, $p$ yang berada diantara $a$ dan $b$ dapat ditulis $p \in[a, b]$.

\section{Definisi 3 (Operator fungsi)}

Fungsi $f: A \rightarrow B$, jika himpunan $A=B$ maka $f: A \rightarrow A$ disebut operator atau tranformasi pada $A$.

\section{HASIL DAN PEMBAHASAN}

\section{Titik-antara di Dalam Ruang Metrik}

Pada bagian ini akan disajikan pengertian titik-antara di dalam ruang metrik serta sifat-sifat yang berkaitan dengannya. Definisi titik-antara didalam ruang metrik $(X, d)$ pertama kali diperkenalkan oleh Menger pada tahun 1928. Definisi yang dimaksud adalah sebagai berikut :

\section{Definisi 2}

Diketahui $(X, d)$ ruang metrik, $p \in X$ disebut titikantara dua titik $a, b \in X$ jika berlaku $d(a, b)=d(a, p)+d(p, b)$.

Definisi diatas mengandung dua pengertian titik-antara yaitu titik-antara sejati dan titik-antara tidak sejati.

Titik $p$ adalah titik-antara dua titik $a$ dan $b$ di dalam $X$ dengan $p \neq a$ dan $p \neq b$ dengan

$d(a, p)+d(p, b)=d(a, b)$ maka titik $p$ disebut titik-antara sejati. Sedangkan jika $p=a$ dan $p=b$ atau salah satunya berbeda, misalnya $p=a$ dan $p \neq b$ dan sebaliknya maka $p$ disebut titik-antara tidak sejati.

\section{Contoh 1}

Titik $p$ adalah titik-antara dalam ruang metrik $(R, d)$, dengan $d(x, y)=|x-y|$,

$\forall x, y \in R$,

maka :

$$
\begin{aligned}
& \begin{aligned}
p=\alpha x+ & (1-\alpha) y \text { dengan } \alpha \in(0,1) \\
d(x, p)+ & d(p, y)=d(x, \alpha x+(1-\alpha) y)+d(\alpha x+(1-\alpha) y, y) \\
& =|x-(\alpha x+(1-\alpha) y)|+|(\alpha x+(1-\alpha) y-y)| \\
& =|(1-\alpha) x-(1-\alpha) y|+|(\alpha x+y-\alpha y-y)| \\
& =|1-\alpha||x-y|+|\alpha||x-y|
\end{aligned}
\end{aligned}
$$




$$
\begin{aligned}
& =(|1-\alpha|+|\alpha|)|x-y| \\
& =|x-y| \\
& =d(x, y)
\end{aligned}
$$

\section{Contoh 2}

Titik $h=\alpha f+(1-\alpha) g \quad$ dengan $\quad \alpha \in(0,1)$ adalah titik-antara dalam ruang metrik $(\mathrm{C}[\mathrm{a}, \mathrm{b}], d)$, dengan $C[a, b]$ adalah koleksi semua fungsi kontinu pada $[a, b]$ dan

$d(f, g)=\sup \{|f(x)-g(x)| ; x \in[a, b]\}$, sebab :

$d(f, h)+d(h, g)=\sup \{|f(x)-h(x)| ; x \in[a, b]\}+\sup \{|h(x)-g(x)| ; x \in[a, b]\}$

$=\sup \{|f(x)-\alpha f(x)-(1-\alpha) g(x)| ; x \in[a, b]\}$

$$
+\sup \{|\alpha f(x)+(1-\alpha) g(x)-g(x)| ; x \in[a, b]\}
$$

$=\sup \{|f(x)-g(x)| ; x \in[a, b]\}$

$=d(f, g)$

\section{Contoh 3}

Titik $h=\alpha f+(1-\alpha) g$ dengan $\alpha \in(0,1) \quad$ adalah titik-antara $x=\left\{x_{i}\right\}$ dan $y=\left\{y_{i}\right\}$ dalam ruang metrik $(C[0,1], d)$ dan $d(f, g)=\int_{0}^{1}|f(x)-g(x)| d x$ dengan $C[0,1]$ adalah

koleksi semua fungsi kontinu pada $[0,1]$,

sebab :

$d(f, h)+d(h, g)=\int_{0}^{1}|f(x)-h(x)| d x+\int_{0}^{1}|h(x)-g(x)| d x$

$=\int_{0}^{1}|f(x)-\alpha f(x)-(1-\alpha) g(x)| d x+\int_{0}^{1}|\alpha f(x)+(1-\alpha) g(x)-g(x)| d x$

$=\int_{0}^{1}(1-\alpha)(f(x)-g(x))\left|d x+\int_{0}^{1}\right| \alpha(f(x)-g(x)) \mid d x$

$=\left|1-\alpha \int_{0}^{1}\right| f(x)-g(x)|d x+| \alpha\left|\int_{0}^{1}\right| f(x)-g(x) \mid d x$

$=(|1-\alpha+| \alpha \alpha) \int_{0}^{1}|f(x)-g(x)| d x$

$=\left|1-\alpha+\alpha \int_{0}^{1}\right| f(x)-g(x) \mid d x$

$=\int_{0}^{1}|f(x)-g(x)| d x$

$=d(f, g)$
Jika $p$ merupakan titik-antara $a$ dan $b$ dalam ruang metrik $(X, d)$. Apakah keantaraan titik $p$ dipertahankan oleh suatu metrik invarian atau suatu fungsi kontraktif ? Sifat-sifat berikut ini merupakan sifat titik-antara dalam ruang metrik invarian fungsi kontraktif.

\section{Definisi 2 (Ruang Metrik Invarian)}

Ruang metrik $(X, d)$ disebut ruang metrik invarian, untuk setiap $a, b, z \in X$ jika berlaku :

$$
d(a+z, b+z)=d(a, b)
$$

\section{Teorema 3}

Jika $(X, d)$ ruang metrik invarian dan $p$ titik-antara dengan $a, b \in X$ maka

$p+z$ titik-antara $a+z, b+z \in X$ untuk setiap $z \in X$.

\section{Bukti :}

$(X, d)$ ruang metrik invarian, berarti untuk setiap $a, b, z \in X$ berlaku :

$d(a+z, b+z)=d(a, b)$

Titik $p$ merupakan titik-antara $a, b \in X$ maka $d(a, b)=d(a, p)+d(p, b)$, dan karena $d$ metrik invarian padanya maka diperoleh :

$d(a, b)=d(a+z, b+z)=d(a+z, p+z)+d(p+z, b+z)=d(a, p)+d(p, b)$

Jadi, $p+z$ titik-antara $a+z, b+z \in X$.

\section{Definisi 3 (Fungsi Kontraktif)}

Fungsi $f: X \rightarrow X$ dengan $(X, d)$ ruang metrik dikatakan kontraktif jika ada bilangan $\alpha$ dengan $0 \leq \alpha \leq 1 \quad$ sehingga berlaku $d(f(x), f(y))=\alpha d(x, y)$ untuk setiap $x, y \in X$ Perhatikan kembali fungsi kontraktif $f: X \rightarrow X$ dengan $(X, d)$ ruang metrik.

Jika titik $p \in X$ merupakan titik-antara $a, b \in X$ dan $f$ fungsi kontraktif pada ruang metrik $(X, d)$. Apakah $f(p)$ adalah titik-antara $f(a)$ dan $f(b)$ ?

Teorema berikut akan menunjukan bahwa titik-antara dalam ruang metrik juga berlaku pada fungsi kontraktif.

\section{Teorema 4}

Diketahui $(X, d)$ ruang metrik dan $f: X \rightarrow X$ adalah fungsi kontraktif. Jika $p$ titikantara $a, b \in X$ maka

$f(p)$ titik-antara $f(a)$ dan $f(b)$.

\section{Bukti :}

Ambil sebarang 
$a, b \in X$. Titik $p$ adalah titik-antara $a, b \in X$, maka :

$$
d(a, b)=d(a, p)+d(p, b)
$$

Karena

$$
f: X \rightarrow X \text { dan } a, b \in X \text { maka } f(a), f(b) \in X \text {. }
$$

Selanjutnya karena $f$ kontraktif maka terdapat bilangan riil $\alpha$ dengan $0 \leq \alpha \leq 1$ dan berlaku :

diperoleh :

$$
d(f(a), f(b))=\alpha d(a, b)
$$

$$
\begin{aligned}
& \quad d(f(a), f(b))=\alpha[d(a, p)+d(p, b)] \\
& =\alpha d(a, p)+\alpha d(p, b) \\
& =d(f(a), f(p))+d(f(p), f(b)) \\
& \text { Jadi } f(p) \text { adalah titik-antara } f(a) \operatorname{dan} f(b) .
\end{aligned}
$$

\section{Teorema 5}

Diketahui

$$
\text { ruang metrik }
$$

$f: X \rightarrow X$ dan $g: X \rightarrow X$ adalah fungsi-fungsi kontraktif. Jika $p$ titik-antara $a, b \in X$, maka $(f \circ g)(p)$ titik-antara $(f \circ g)(a)$ dan $(f \circ g)(b)$

\section{Bukti :}

Diketahui

$g: X \rightarrow X$ kontraktif, berarti ada bilangan $\alpha$ dengan $0 \leq \alpha \leq 1$, sehingga $\quad d(g(a), b(b))=\alpha d(a, b)$ $f: X \rightarrow X$ kontraktif, inil ber arti terdapat bilangant $\beta$ dengan $0 \leq \beta \leq 1$ Akibatnya :

$$
\begin{aligned}
d(f o g & (a), f \circ g(b))=d(f(g(a)), f(g(b))) \\
& =\beta d(g(a), g(b)) \\
& =\beta\{\alpha d(a, b)\} \\
& =\beta\{\alpha(d(a, p)+d(p, b)\} \\
& =\beta\{\alpha d(a, p)+\alpha d(p, b)\} \\
& =\beta\{d(g(a), g(p))+d(g(p), g(b))\} \\
& =d(f(g(a)), f(g(p)))+d(f(g(p)), f(g(b))) \\
& =d(f \circ g(a), f \circ g(p))+d(f \circ g(p), f \circ g(b))
\end{aligned}
$$

Jadi, $(f \circ g)(p)$ titik-antara $(f \circ g)(a)$ dan $(f \circ g)(b)$

\section{Ruang Interval Metrik}

Operator $A: X^{2} \rightarrow 2^{X}$ dengan $X \neq \varnothing$ disebut operator interval, jika $A(a, a)=\{a\}$, $a, b \in A(a, b)$ dan $A(a, b)=A(b, a)$ untuk setiap $a, b \in X$. Oleh karena itu, jika $A$ merupakan operator interval pada $X$, maka koleksi semua $A(a, b)$ dengan $a, b \in X$ disebut ruang interval dan dituliskan dengan $(X, A)$. Sebagai contoh, diketahui $X=\{1,2,3,4,5\}$. Didefinisikan $A(a, b)=\{x: x \in X$ dan $a \leq x \leq b$ atau $b \leq x \leq a\}$ untuk setiap $a, b \in X$. Dapat ditunjukan bahwa $A$ operator interval pada $X$. Jadi $(X, A)$ adalah ruang interval. Pada bagian ini akan dibahas tentang ruang interval metrik (metric interval space).

Operator interval yang akan dibahas dikhususkan pada ruang metrik $(X, d)$. Definisi berikut menyatakan bahwa didalam ruang metrik $(X, d)$ terdapat suatu operator $A_{d}$. Operator interval ini akan dibicarakan lebih lanjut.

\section{Definisi 4 (Ruang Interval Metrik)}

Diketahui ruang metrik $(X, d)$. Jika ada operator $A_{d}$ pada $X$, maka operator interval ini disebut operator interval metrik (metric interval operator). Selanjutnya pasangan $\left(X, A_{d}\right)$ disebut ruang interval metrik (metric interval space).

\section{Definisi 5 (Mixing Operator)}

Operator $\quad M: X^{3} \rightarrow 2^{X} \quad$ yang didefinisikan $M(a, b, c)=A(a, b) \cap A(a, c) \cap A(b, c)$ untuk setiap $a, b, c \in X$ disebut mixing operator atau operator-M yang dibangkitkan oleh operator interval $A$ pada $X$.

\section{Teorema 6}

Jika $M$ adalah mixing-operator pada ruang interval $(X, A)$, maka :

(1) $M(a, a, a)=M(a, a, b)=\{a\}$

(2) Jika $\sigma$ adalah permutasi $a, b, c \in X$, maka

$$
M(\sigma(a, b, c))=M(a, b, c)
$$

\section{Bukti :}

$M(a, a, a)=M(a, a)=\{a\} . M(a, a, b)=A(a, a) \cap A(a, b)$. Karena

$$
\begin{aligned}
& A(a, a) \subseteq A(a, b), \text { maka } \\
& A(a, a) \cap A(a, b)=A(a, a)=\{a\} . \text { Jadi } \\
& M(a, a, a)=M(a, a)=\{a\} . \text { Terbukti }(1) .
\end{aligned}
$$

Untuk membuktikan (2), diambil sebarang $a, b, c \in X$.

\section{Pertama,}

perlihatkan bahwa

$M(a, a, b)=M(a, b, a)=M(b, a, a)$.

Dengan menggunakan definisi mixing operator $M$ dan sifat irisan himpunan, diperoleh :

$M(a, a, b)=A(a, a) \cap A(a, b)=A(a, a)=\{a\}$ 
$M(a, b, a)=A(a, b) \cap A(a, a) \cap A(b, a)=A(a, a)=\{a\}$

$M(b, a, a)=A(b, a) \cap A(a, a)=A(a, a)=\{a\}$.

Jadi $M(a, a, b)=M(a, b, a)=M(b, a, a)$.

Dengan cara yang sama dapat diperlihatkan $M(a, a, c)=M(a, c, a)=M(c, a, a)$

$M(b, b, a)=M(b, a, b)=M(a, b, b)$

$M(b, b, c)=M(b, c, b)=M(c, b, b)$

$M(c, c, a)=M(c, a, c)=M(a, c, c)$, dan

$M(c, c, b)=M(c, b, c)=M(b, c, c)$.

\section{Kedua,}

diperlihatkan

$M(a, b, c)=M(a, c, b)=M(c, a, b)=M(c, b, a)=M(b, c, a)$

$=M(b, a, c)$.

Dengan menggunakan definisi mixing-operator $M$ dan sifat irisan himpunan, diperoleh

$$
\begin{aligned}
M(a, b, c) & =A(a, b) \cap A(a, c) \cap A(b, c) \\
& =A(a, c) \cap A(a, b) \cap A(c, b)=M(a, c, b) \\
& =A(c, a) \cap A(a, b) \cap A(c, b) \\
& =A(c, a) \cap A(c, b) \cap A(a, b)=M(a, c, b) \\
& =A(c, b) \cap A(c, a) \cap A(a, b) \\
& =A(c, b) \cap A(c, a) \cap A(b, a)=M(c, b, a) \\
& =A(b, c) \cap A(c, a) \cap A(b, a) \\
& =A(b, c) \cap A(b, a) \cap A(c, a)=M(b, c, a) \\
& =A(b, a) \cap A(b, c) \cap A(c, a) \\
& =A(b, a) \cap A(b, c) \cap A(a, c)=M(b, a, c)
\end{aligned}
$$

maka $M(\sigma(a, b, c))=M(a, b, c)$ dengan $\sigma$ adalah permutasi $a, b, c \in X$.

\section{KESIMPULAN}

Berdasarkan pembahasan maka kesimpulan dalam penelitian ini adalah:

1. Di dalam ruang metrik $(X, d)$, jika $p \in X$ merupakan titik-antara $a, b \in X$, maka berlaku sifat-sifat :

a.) Jika $d$ metrik invarian, maka $p+z$ titik-antara $a+z$ dan $b+z$ untuk setiap $z \in X$

b.) Jika $f$ fungsi kontraktif dari $X$ ke $X$, maka $f(p)$ titik-antara $f(a)$ dan $f(b)$

c.) Jika $f$ dan $g$ fungsi-fungsi kontraktif dari $X$ ke $X$, maka $(f \circ g)(p)$ titik-antara $(f \circ g)(a)$ dan $(f \circ g)(b)$

2. Interval $A_{d}(a, b)$ merupakan himpunan semua titikantara dua titik $a$ dan $b$ di dalam ruang metrik $(X, d)$, maka

$A_{d}(a, b)=\{p \in X \mid d(a, p)+d(p, b)=d(a, b)\} \quad$ disebut interval metrik. Karena interval metrik $A_{d}$ merupakan operator interval metrik, maka $\left(X, A_{d}\right)$ disebut ruang interval metrik. Selanjutnya sesuai definisi titik-antara di dalam ruang metrik, titik $p$ di dalam ruang metrik berada di antara $a$ dan $b$ di dalam $X$, jika jika $d(a, b)=d(a, p)+d(p, b)$. Apabila semua titik-antara dua titik $a$ dan $b$ di dalam $X$ dikumpulkan, maka akan terbentuk suatu himpunan dengan $a$ dan $b$ menjadi anggotanya. Himpunan ini disebut interval dengan ujung-ujung $a$ dan $b$, yang selanjutnya dinotasikan $A_{d}(a, b)$. Interval ini disebut interval metrik.

\section{DAFTAR PUSTAKA}

Bartle, R. G. \& Shertbert, D. R (1994). Introduction to Real Analysis. Second Edition. John Wiley \& Sons. Inc, New York.

Conway, J.B. (1990) A Course in Functional Analysis. Springer-Verlag, New York

Kreyszig, E. (1978) Intrduction Functional Analysis with Applications. John Wiley and Sons, New York.

Soeparna, D. (2006) Pengantar Analisis Real. Jurusan Matematika FMIPA Universitas Gadjah Mada, Yogyakarta.

Soeparna, D. (2007) Pengantar Analisis Abstrak. Jurusan Matematika FMIPA Universitas Gadjah Mada, Yogyakarta. 